Gut, 1986, 27, 942-945

\title{
Acid perfusion of duodenal ulcer craters and ulcer pain: a controlled double blind study
}

\author{
J Y KANG, I YAP, R GUAN, AND H H TAY \\ From the Department of Medicine, National University of Singapore, Singapore
}

SUMmARY Although early studies attributed an important role to acid in the pathogenesis of duodenal ulcer pain, recent reports are conflicting. The aim of the present study is to determine whether direct acidification of the duodenal ulcer crater in symptomatic patients reproduces ulcer pain. Patients with endoscopically diagnosed duodenal ulcers were studied. No premedication or sedation was given. A washing tube was passed via the endoscope and $0 \cdot 1 \mathrm{~N}$ hydrochloric acid as well as normal saline were sequentially administered on to the ulcer crater, the sequence of infusion being randomised and double blind. Forty patients were studied. Sixteen developed typical ulcer pain during acid infusion compared with four with saline $(\mathrm{p}<0.005)$. Ten patients who developed pain on acid were rechallenged with acid after their pains disappeared. Typical pain recurred in all. Twenty patients without duodenal ulcer did not develop pain when $200 \mathrm{ml}$ of $0 \cdot 1 \mathrm{~N}$ hydrochloric acid was infused into the duodenum. Acid therefore appears to have a definite role in the pathogenesis of duodenal ulcer pain although other factors may also be important.

The pathogenesis of pain in duodenal ulcer is unclear. Early studies by Palmer ${ }^{1}$ and Pickering ${ }^{2}$ suggested a close relationship between gastroduodenal acidity and ulcer pain. These studies were, however, unblinded and largely uncontrolled and later workers ${ }^{3-5}$ reported more equivocal results. Harrison et $a l^{5}$ recently studied gastroduodenal acidification in duodenal ulcer and concluded that duodenal ulcer pain is largely and possibly totally unrelated to the presence of acid in the duodenum. The aim of the present study is to reinvestigate the relationship of duodenal ulcer pain and duodenal acidity by direct administration of acid onto duodenal ulcers craters in a controlled, double-blind fashion.

\section{Methods}

PATIENT SELECTION

Patients who reported upper abdominal pain within the last 24 hours and in whom active duodenal ulcers were endoscopically diagnosed were studied. Those with recent upper gastrointestinal haemorrhage or serious underlying diseases were excluded. A control group of 20 patients undergoing endoscopy but

Address for correspondence: Dr J Y Kang, University Department of Medicine II, Singapore General Hospital, Singapore 0316.

Received for publication 21 November 1985. without duodenal ulcer was also studied. Informed consent was obtained.

\section{STUDY DESIGN}

Endoscopy was carried out under local anaesthesia using the Olympus GIFQ or Q10 gastroscope. No sedation or premedication was given. A washing tube was passed through the biopsy channel of the gastroscope. Through this tube $0.1 \mathrm{~N}$ hydrochloric acid and normal saline were administered sequentially onto the duodenal ulcer crater. For the first 20 patients (group 1) $100 \mathrm{ml}$ of each solution was infused over five minute periods whereas for the next 20 patients (group 2) $200 \mathrm{ml}$ of each solution was infused over 10 minute periods. The order of infusion was randomised and double blind.

The endoscopist periodically adjusted the position of the washing tube to maintain a good flow directed onto the ulcer crater. During the infusion the patient was asked to indicate by hand signals whether abdominal pain developed, exacerbated or improved, and whether the pain was similar to ulcer pains normally experienced in terms of site and character. A person other than the endoscopist made these enquiries and he was unaware of the order of infusion. If typical ulcer pain developed or if pre-existing pain was exacerbated during infusion of one solution, that infusion was ceased and the 
second solution given. If pain disappeared the patient was rechallenged with the first solution.

For each control patient $200 \mathrm{ml}$ of $0.1 \mathrm{~N} \mathrm{HCl}$ was infused into the duodenal cap over 10 minutes and the patients were asked whether abdominal pain developed.

\section{Results}

PATIENT CHARACTERISTICS

Forty ulcer patients were studied. Thirty six were men and four women. There were 27 Chinese, nine Indians, three Eurasians and one Malay. Their ages ranged from 19 to 75 years.

\section{PATIENTS REPORTING PAIN ON ACID OR SALINE Group 1}

One hundred millilitres each of acid and saline given. Of 20 patients, seven developed typical ulcer pain or reported exacerbation of pain already present during acid infusion. One of the seven also developed his usual ulcer pain while saline was being given. Another patient reported an atypical abdominal pain during acid infusion.

\section{Group 2}

Two hundred millilitres each of acid and saline given. Nine of 20 patients reported typical ulcer pains on acid. Three developed pain on saline: two of these also had pain with acid. One other patient reported an atypical pain on acid. Of the nine who had typical pain with acid, six developed their pains during the first $100 \mathrm{ml}$ of infusion while in the other three pain occurred during the second $100 \mathrm{ml}$. Thus, of the patients who remained pain free after administration of $100 \mathrm{ml}$ of acid, three out of 14 $(21 \%)$ developed pain during the second $100 \mathrm{ml}$. Pain on saline infusion was stated to be mild in all four patients.

\section{Overall results}

These are shown in the Table. Sixteen patients $(40 \%)$ developed ulcer pains when their ulcers were perfused with acid compared with four $(10 \%)$ when

Table Development of duodenal ulcer pain during acid or saline administration

\begin{tabular}{llll}
\hline & Pain & No pain & Total \\
\hline Acid & 16 & $24^{*}$ & 40 \\
Saline & 4 & 36 & 40 \\
\hline
\end{tabular}

$p<0.005$.

* Including two patients with atypical pain. saline was used. This difference was statistically significant $(\mathrm{p}<0.005)$ using the $\chi^{2}$ test with Yate's correction.

Patients who developed pain during acid infusion did not differ from those who had no pain in terms of age, length of history or the interval from the last episode of pain.

Time taken for pain to occur

For the 13 patients who developed pain within the first five minutes of acid infusion the mean volumes of acid infused before pain occurred was $57 \mathrm{ml}$ (range 15-100 ml). The three who reported pain after five minutes developed their pains after 105 , 130 , and $170 \mathrm{ml}$ of acid. For the four who developed pain during saline infusion the pain occurred after $10,60,100$, and $170 \mathrm{ml}$ respectively.

\section{Influence of the order of infusion}

In 25 patients acid was given before saline and pain occurred during acid infusion in nine $(36 \%)$. The mean volume of acid given before pain was reported was $72 \mathrm{ml}$ (range $15-130 \mathrm{ml}$ ). In 15 patients saline was given before acid and seven $(47 \%)$ developed pain during acid infusion. The mean volume of acid given before pain occurred was $68 \mathrm{ml}$ (range $20-150 \mathrm{ml}$ ). The mean volume of fluid (acid or saline) given before pain occurred in the latter group of patients was $225 \mathrm{ml}$ (range 120 to $350 \mathrm{ml}$ ).

\section{RECHALLENGE}

Of the patients who developed typical ulcer pains during acid infusion 10 were rechallenged with a further infusion of acid after their pains had disappeared during saline administration. Typical pains recurred in all 10. One patient with atypical pain on acid was similarly rechallenged but his pain did not recur. Rechallenge was not done in any of the four subjects reporting pain during saline infusion because of pain being transient (two patients) and/or because of pain also occurring during acid infusion (three patients).

\section{CONTROL PATIENTS}

None of the 20 control patients reported abdominal pain during acid infusion into the duodenum. One, however, reported a retrosternal burning sensation.

\section{Discussion}

It is a common clinical impression that duodenal ulcer pain is aggravated by hunger and relieved by food, antacids, and vomiting. It seems therefore that duodenal ulcer pain is related to gastroduodenal acidity. Early studies by Palmer and Pickering confirmed this view. Palmer ${ }^{1}$ instilled acid into the 
stomach or duodenum in peptic ulcer patients whose last episode of pain occurred within the last 24 hours. Typical ulcer pain occurred in 314 out of 324 instances. Up to $600 \mathrm{ml} 0.5 \%$ hydrochloric acid $(0 \cdot 135 \mathrm{~N})$ was given, however, and in some instances it took more than one hour before pain occurred. Bonney and Pickering ${ }^{2}$ instilled up to $300 \mathrm{ml} 0 \cdot 1 \mathrm{~N}$ hydrochloric acid into the stomachs of peptic ulcer patients during days when they experienced spontaneous ulcer pain. In eight out of nine cases pain was reproduced. Pain was not induced by similar amounts of normal saline. These authors also observed that spontaneous pain tended to occur during times of low intragastric $\mathrm{pH}$. Aspiration of gastric contents during pain tended to relieve it while reintroduction tended to bring on the pain again.

More equivocal results were reported by subsequent workers. Ruffin ${ }^{3}$ repeated Palmer's acid experiments but only 37 of 100 patients experienced ulcer pain with acid. Texter and his colleagues, ${ }^{4}$ again repeating Palmer's experiments, obtained a positive test in 54 of 155 cases. Although Smith produced pain by acid instillation in most peptic ulcer subjects, individual episodes of spontaneous pain were unrelated to gastric $\mathrm{pH} .^{5}$

These observations obtained in the pre-endoscopy era were, however, unblinded and largely uncontrolled. More recently Harrison $e t a t$ infused citric or hydrochloric acid into the stomach of patients with active symptomatic duodenal ulcer. Only one of 13 subjects reported typical ulcer pain. Infusion of sodium citrate at $\mathrm{pH} 7$ did not cause pain. These authors concluded that duodenal ulcer pain was largely and possibly totally unrelated to duodenal acidification. Joffe, on the other hand, was able to produce pains in duodenal ulcer subjects by introduction of acid into the duodenum. ${ }^{7}$ Administration of normal saline or sodium bicarbonate did not cause pain. Our results are also different from those of Harrison et al. One possible explanation is the different amounts of acid entering the duodenum. In Harrison's study the mean amounts of acid entering the duodenum varied from 23-27 mmol over 30 minute periods. This compares with the $10-20 \mathrm{mmol}$ over five to 10 minutes used in Joffe's and our own experiments. While the amounts of acid we used are more than those occurring under physiological conditions, it may be that such large amounts are needed to consistently reproduce pain. Duodenal $\mathrm{pH}$ is widely variable from place to place ${ }^{8}$ and it may be that a critical concentration of acid at the site of the ulcer is required to produce pain. This critical concentration may be reached only intermittently under physiological conditions but more frequently during our experiments. As under basal conditions duodenal ulcer pain occurs only intermittently it is perhaps not surprising that the near physiological amounts of acid entering the duodenum in Harrison's experiments led to pain in only a small proportion of cases.

James and Kenefick, ${ }^{910}$ using a protocol similar to ours, infused acid directly onto gastric ulcers in eight patients. None reported pain. It was not stated, however, whether the patients were actively symptomatic at the time of study. Another difference from our study is that atropine was used for premedication.

In our study $33 \%$ of patients experienced pain during infusion of $10 \mathrm{mmol}$ of hydrochloric acid over five minutes. Of those who did not experience pain after the first $10 \mathrm{mmol}$ of acid $21 \%$ developed pain while a further $10 \mathrm{mmol}$ of acid was being given. It would be of interest to continue the infusions until $300 \mathrm{ml}$ or more has been given. This would, however, make the duration of the experiments unacceptable to the patients. Our data suggest that pain may be produced by acid infusion in more than $40 \%$ of patients with active symptomatic duodenal ulcer provided the infusion is continued for long enough.

The pathogenesis of ulcer pain in the remaining $60 \%$ of our patients remains unclear. While it is possible that prolonged periods of acid infusion may bring on the pain, factors other than acid may also be involved. The latter possibility is supported by our finding of pain occurring during saline infusion in four patients, and also by the equivocal results obtained when the pain relieving effect of antacids was tested in placebo controlled studies. Sturdevant et $a l,{ }^{11}$ for instance, reported no significant difference between antacid and placebo with regard to pain relief. Two other studies ${ }^{12} 13$ showed a difference in favour of antacid while a fourth study was equivocal. ${ }^{14}$

Altered gastroduodenal motility or spasm is another factor that may contribute to the pathogenesis of ulcer pain. Wilson ${ }^{15}$ had observed that pain in duodenal ulcer was associated with sustained contraction of the duodenal bulb. Ruffin ${ }^{3}$ found that duodenal ulcer pain was invariably related to delay of gastric evacuation or spasm at the ulcer site. Texter $e t a l^{4}$ reported that ulcer pains were accompanied by increased intraluminal pressure and delayed gastric emptying while relief of pain accompanied resumption of gastric evacuation. Palmer and Pickering, however, felt that this was at most a minor factor. ${ }^{1} 21617$ Further studies are required in this area using modern and more rigorous methodology. It is also possible that acid is one of several factors which cause ulcer pain by affecting gastroduodenal motility. 
Part of this study was presented at the Autumn meeting of the British Society of Gastroenterology, Liverpool, UK, September 1984.

\section{References}

1 Palmer WL. The mechanism of pain in gastric and duodenal ulcer (ii) The production of pain by means of chemical irritants. Arch Intern Med 1926; 38: 694-707.

2 Bonney GLW, Pickering GW. Observations on the mechanism of pain in ulcer of the stomach or the duodenum. Part I-the nature of the stimulus. Clin Sci 1946; 6: 65-89.

3 Ruffin JM. Mechanism of ulcer pain and significance of pain patterns. Am J Dig Dis 1959; 4: 871-4.

4 Texter EC, Vantrappen GR, Lazar HP, Puletti EJ, Barborka CJ. Further observations on the mechanism of ulcer pain. Ann Intern Med 1959; 51: 1275-94.

5 Smith AWM. The pain of peptic ulceration. $Q J \mathrm{Med}$ 1955; 24: 392-407.

6 Harrison A, Isenberg JI, Schapira M, Hagie L. Most patients with active symptomatic duodenal ulcers fail to develop ulcer-type pain in response to gastroduodenal acidification. J Clin Gastroenterol 1982; 4: 105-8.

7 Joffe SN, Plumrose JN. Pain provocation test in peptic duodenitis. Gastrointest Endosc 1983; 29: 282-4.
8 Lam SK. Pathogenesis and pathophysiology of duodenal ulcer. Clin Gastroenterol 1984; 13: 447-72.

9 James O, Kenefick JS. Pain in gastric ulcer. [Letter]. Lancet 1974; 1: 562.

10 James O, Kenefick JS. Pain in peptic ulcer. Proc $R$ Soc Med 1975; 68: 286-7.

11 Sturdevant RAL, Isenberg JI, Secrist D, Ansfield J. Antacids and placebo produced similar pain relief in duodenal ulcer patients. Gastroenterology 1977; 72: 1-5.

12 Rune SJ, Zachariassen A. Relief of epigastric pain by antacids in duodenal ulcer patients. Scand J Gastroenterol 1979 suppl. 15: 41-5.

13 Lorber SH, Stelzer FA, Mayer EM. Effect of antacid and placebo on pain of duodenal ulcer. [Abstract]. Gastroenterology 1978; 74: 1058.

14 Littman A, Welch R, Fruin RC, Aronson AR. Controlled trials of aluminum hydroxide gels for peptic ulcer. Gastroenterology 1977; 73: 6-10.

15 Wilson MJ. Duodenal ulcer. Observations on the behaviour of stomach and duodenum in the presence of pain. Arch Intern Med 1928; 41: 633-41.

16 Palmer WL. The mechanism of pain in gastric and duodenal ulcer. (III). The role of peristalsis and spasm. Arch Intern Med 1927; 39: 109-33.

17 Palmer WL, Heinz JE. The mechanism of pain in gastric and duodenal ulcers. (VII). Further observations. Arch Intern Med 1934; 53: 269-308. 